\title{
Effects of Personality on Social Performance in Social Trading
}

\author{
Quanchen Liu \\ Shanghai Jiao Tong University \\ wslqc999@sjtu.edu.cn
}

University of Science and

Technology of China

itzhu@mail.ustc.edu.cn

\author{
Bingqing Xiong \\ University of Science and \\ Technology of China \& City \\ University of Hong Kong \\ bxiong2-c@my.cityu.edu.hk
}

\author{
Eric Lim \\ University of New South Wales \\ e.t.lim@,unsw.edu.au
}

\author{
Zhao Cai \\ University of Nottingham Ningbo \\ China \\ zhao.cai@nottingham.edu.cn
}

\author{
Chee-Wee Tan \\ Copenhagen Business School \\ ct.digi@cbs.dk
}

\begin{abstract}
On social trading platforms, the income of leader traders is largely dictated by the number of copy trades conducted by their followers. Consequently, it is imperative for leader traders to exhibit appealing personalities to entice their followers to conduct copy trades. Drawing on social capital theory, we endeavor to scrutinize the effects of traders' personalities on the accumulation of social capital, which in turn bolsters social performance as measured by the number of copy trades. Data was extracted from a leading social trading platform. The Myers-Briggs Type Indicator personality classification system was then employed to depict leader traders' personalities based on a novel text-based, machine learning approach. Preliminary analytical results reveal significant relationships among personality traits, social capital dimensions, and social performance. Findings from this study generate insights for social trading platforms and leader traders on exhibiting desirable personalities conducive for accumulating social capital that entice followers to conduct copy trades.
\end{abstract}

\section{Introduction}

The emergence of social trading platforms has revolutionized conventional trading markets by giving rise to transparent and trustworthy online communities where millions of worldwide investors discuss, share, and learn investment strategies [1]. This in turn has spurred a surge of investors participating on social trading platforms with estimated investments of over $€ 2$ billion in 2020 alone [2]. There are two main groups of users on social trading platforms: leader traders (as signal providers) and followers (as signal followers) [3]. Leader traders share investment strategies and release signals in the form of executed trades. Followers can then utilize the copy trading service offered by social trading platforms to automatically duplicate and execute trades broadcasted by leader traders after paying a certain amount of subscription fee. In this sense, leader traders profit from their own trading activities and from dividends earned through followers' copy trades [3]. Consequently, instead of amassing sheer numbers of followers, leader traders are primarily concerned with convincing their followers to conduct copy trading to reap long-term benefits from the community.

To generate returns from followers, leader traders have to cultivate a conducive atmosphere in their traderfollowers community. A vibrant communal atmosphere, comprising interactive discussion, knowledge sharing, and timely Q\&A, not only strengthens social interactions among members but it also increases communities' stickiness over time [4-6]. Prior research has demonstrated that individuals' personality traits affect the quality and quantity of their social relationships [7]. Scholars have found that personality (how people are) is closely tied to social relationships (who people are with) [8]. It has been claimed that individuals with friendly and outgoing personalities are likely to have greater contact frequency and maintain high-quality social relationships [7-10]. In this sense, individual personality plays an instrumental role in accumulating social capital, represented by the social connections and relational assets embedded in interactive social relationships. With abundant social capital, individuals can interact with community members effectively and attain a high level of social performance, defined as the communal outcome for individuals and collective actors derived from their underlying social structure [11]. In the context of social trading, a leader trader's social performance reflects the profit earned from his/her followers as measured by the total number of copy trades. Conceivably, we posit social performance as a focal consequence of leader traders' exhibition of their personalities and attempt to provide an answer to the following research question: 
how do leader traders' personalities influence their social performance via the accumulation of social capital?

Although extant literature on social trading platforms has contributed to an in-depth appreciation of the factors driving investors' trading performance, there is a dearth of research that has explored leader traders' social performance as represented by the status of the communities they led $[1,3,12]$. Unlike traditional investment markets in the likes of bonds, equity, and real estate, social trading enables leader traders to profit from their communities through being rewarded a fraction of the subscription fee generated from copy trades. Social performance is hence a key motivation for leader traders to interact with their followers. Besides, despite the intrinsic influence of personality on social relationships, research on social psychology has long neglected the role of personalities in social phenomena [8]. Due to difficulties in quantifying individual investors' transactions and social connections based on secondary data, there is a paucity of empirical studies on the role of social interactions in influencing social performance [13].

To disentangle the effects of leader traders' personality on social performance, we draw on MyersBriggs Type Indicator (MBTI) personality classification system to arrive at Extraversion-Introversion (E/I), Sensing-Intuition $(\mathrm{S} / \mathrm{N})$, Thinking-Feeling $(\mathrm{T} / \mathrm{F})$, and Judging-Perceiving $(\mathrm{J} / \mathrm{P})$ as four dimensions depicting trader's personality. Next, building on the social capital framework derived from Nahapiet and Ghoshal [14], we identify structural, cognitive, and relational capital as three dimensions of social capital embedded within communities. To validate our proposed hypotheses of the impact of leader traders' personality on social performance, data was collected from a leading forex social trading platform. Leader traders' personality was ascertained by a machine learning model that extracts MBTI personality types from traders' published text postings. Social capital and traders' social performance were measured by historical social interaction and trading data on the platform. We employed PLS-SEM model to estimate the relationships among personality, social capital, and social performance.

This preliminary study is expected to contribute to extant literature on three fronts. First, while contemporary research on social trading platforms is centered on traders' portfolio performance [3, 15] and behavioral biases $[1,16,17]$, we expand this line of work by investigating how leader traders' social performance can be enhanced. Particularly, we attest to the importance of traders' personalities in fostering engaging communities to encourage copy trading. Second, we elucidate the influence of traders' personalities on social performance by unpacking the interdependencies between personality and social capital. Specifically, we construct a research model to capture the interdependencies between personality traits and social capital dimensions. We leverage on social capital to delineate community atmosphere, thereby advancing studies on online community sociability. Third, distinct from traditional self-report methods to measure traders' personality traits on social trading platforms $[18,19]$, we develop a machine learning model to extract personality traits more accurately than baseline models. In so doing, we aim to deliver a nonintrusive and scalable means of automatically detecting the personality of large numbers of platform users based on their text postings [20].

\section{Theoretical Background}

\subsection{Personality Dimensions}

Personality is defined as the relatively enduring patterns of thoughts, feelings, and behaviors that distinguish individuals from one another [21]. Modern trait theory tries to model personality by setting some classification dimensions and constructing a questionnaire to measure them [22]. Amongst the frameworks used in measuring personality, two of the most popular and reliable ones are the Five-Factor Model (Big-Five Model) [23] and the Myers-Briggs Type Indicator (MBTI) [24].

In this work, the MBTI measurement is adopted for individual personality classification because: a) it achieves the best performance among the state-of-theart personality detection methods reported in Mehta et al. [25]; b) the MBTI measurement is widely accepted in both academia and industry regarding individuals' influence in social media contexts $[25,26]$, which makes it appropriate to be applied in social trading platforms. The MBTI personality classification system is divided into four binary orthogonal personality dimensions, comprising 16 types [27, 28]. Those four dimensions are (1) Extraversion/Introversion (E/I), a measurement of an individual's preference to the outer world or inner world, (2) Sensing/iNtuition (S/N), a measurement on preference to either focusing on basic information or tending to interpret and add meaning, (3) Thinking/Feeling (T/F), a measurement on preference to either logic or emotional when making decisions, and (4) Judgment/Perception ( $\mathrm{J} / \mathrm{P})$, a measurement on preference to a planned and ordered life versus a flexible and spontaneous life. 


\subsection{Social Capital Theory}

Social capital refers to social connections and relational assets, such as norms and identity, embedded therein, and the benefits derived from social relationships $[14,29]$. The ability to form and maintain social relationships is crucial for creating social capital [30]. Over the last few decades, multidisciplinary scholars have leveraged to explain various social phenomena and influences due to its intriguing integration of sociology and economics. Social capital provides access to tangible and intangible social resources, such as increased accessibility to useful information [11] and social support interactions [31], to facilitate social relationships within communities. It creates an atmosphere that is favorable to economic activities and supports jointly solving problems in communities [29, 32].

Social capital is multidimensional, involving various aspects of social structure and interaction. According to Nahapiet and Ghoshal [14], social capital comprises three dimensions: structural, relational, and cognitive capital [33]. Structural capital refers to the properties of the social system and the network of relations as a whole [14]. It describes the basic social structure, including the impersonal configuration of linkages between people, that is, the level of structural embeddedness of a community [32, 34]. Relational capital represents the quality and nature of social relationships [35] or relational embeddedness [14]. The distinctive aspects are trust and trustworthiness, obligations and expectations, and identity and identification [14, 34]. Finally, the cognitive dimension of social capital relates to resources that promote shared understanding and interpretations among individuals engaged in communications [14]. It involves shared language, values, attitudes, beliefs, and goals that lay the foundation for exchanging ideas [36, 37].

\section{Hypotheses Formulation}

\subsection{Social Capital and Social Performance}

Social capital theory is an appropriate theoretical lens for examining the existence, maintenance, and consequences of social relationships inherent in online social trading communities [33]. Research has attested that a higher level of social capital is associated with better economic performance in trading markets [38]. For example, it has been found that better connected agricultural traders have significantly more extensive sales and value-added than less connected counterparts [39]. As an essential instrument for leader traders to share their trading strategies and respond to followers' comments, social communities can bring traders considerable social performance in social trading platforms. This assertion is echoed by Shive [40] who examined the role of social influence is in influencing individual investors' daily trading and stock returns.

In online social trading communities, social interaction ties are created through the subscription of followers and conversation initiated by the trader, structural capital embedded in communities [41]. Furthermore, well-performing investors are more willing to share their experiences, making followers reevaluate their strategies [41]. Besides, followers can also assess their subscribed traders by rating scores, such as the trader's trading profitability, descriptive strategy consistency and recommendation ratings, to evaluate trader's investment strategies, which influences the cognitive capital embedded in the community. Finally, traders and followers will gradually establish trust, identity, and value identification in the community during daily communications, conceived as relational capital [12]. Therefore, we hypothesize a positive relationship between social capital and social performance.

Hypothesis 1: Social capital embedded within the social trading community represented by structural capital, cognitive capital, and relational capital is positively associated with traders' social performance.

\subsection{Personality and Social Capital}

Recent literature on psychology and social media has shown that personality shapes individuals' ability to build social capital in all dimensions [42-44]. Personality plays a crucial role in helping traders better understand themselves and deal with relationships with followers. Personality can be characterized as interindividual differences in how they think and feel about others and themselves when interacting with others [45]. Those thoughts and feelings are largely determined by personality traits [8]. Conceivably, the accumulation of social capital is influenced by the personalities of individuals. For structural capital, personality is conducive to shaping social network structure (i.e., indegree and brokerage), thereby helping individuals occupy advantageous network positions [46, 47]. Meanwhile, personality provides necessary cognitive and emotional resources to maintain social contacts, supporting cognitive capital development [42, 48]. As to relational capital, personality affects interpersonal social behaviors $[49,50]$, which leads to the accumulation of relational resources received from social relationships [51]. It has been found that individuals exhibit personality-like differences in their online social interaction and communication choices and styles $[49,50]$, which induces distinctive effects on 
the development of social capital embedded in communities.

People with higher scores in Extroversion are considered more gregarious, friendly, outgoing, and sociable than the opposite ones who have a high level of Introversion [52]. Extraversion is beneficial for social capital because extraverted traders tend to pursue more social associations among their followers. Extant studies have reported that extraverts have more extensive personal networks [53] and more energetic engagement in conversations [54] with a higher frequency of meeting their friends [9]. As a consequence, they are more likely to maintain active friendships [9, 42]. Furthermore, it is relatively easy for extroverts to attain social support from their network [55], strengthening the trust and reciprocity within their community. Therefore, it is expected that a positive relationship exists between Extroversion personality and traders' social capital. Accordingly, we propose the following hypothesis:

Hypothesis 2a: While Extraversion personality is positively associated with traders' social capital, the association is strongest for structural capital.

People with higher scores in Sensing are more realistic, down-to-earth, practical, pragmatic, and probably slow to change than ones in iNtuition who are adventurous, intellectually curious, and interested in new ideas [52]. Sensing traders are prone to focus on professional investment by sticking to a relatively robust trading portfolio for long-term returns instead of chasing profit from social relationships $[27,56]$. Therefore, they take less consideration of socializing with followers and engage in online social activities less often. Due to infrequent participation in social interactions such as online discussions and communications, they are more likely to have weaker social network ties, leading to limited resources in developing social contacts, thereby increasing the difficulty of building trustworthy and reciprocal social networks. Hence, sensing personality is negatively related to social capital:

Hypothesis 2b: While Sensing personality is negatively associated with traders' social capital, the association is strongest for relational capital.

Individuals with a high score in the Thinking dimension are more consistent, logical, impersonal, truth-based, and sometimes uncaring or indifferent than their counterparts scoring high in Feeling who prefer a caring, harmonious, and tactful interpersonal relationship [52]. Thinking personality might be negatively related to social capital because this personality shows less prosocial characteristics and tends to have arm's-length relationships. Due to such innate personality traits, they are unlikely to extend their social networks by actively participating in social interactions. Showing uncaring or ascetic on social relationship, they are less cooperative in being involved in online interpersonal communication and possibly blind to respond to the needs of others [49]. Based on these inferences, we argue that traders in Thinking are likely to invest limited resources to maintain social contacts since they might to a large extent need to keep a logic investing brain rather than being affected by social comments and feedbacks. Thus, we propose the following hypothesis:

Hypothesis 2c: While Thinking personality is negatively associated with traders' social capital, the association is the strongest for cognitive capital.

Individuals with Judging personality prefer a planned or orderly way of life, having things organized, and orienting tasks under control [52]. They can confine their impulses into reasonable boundaries, which allows them to act responsibly. Benefited by the intrinsic idiosyncrasy of the self-control embedded within this personality, a positive relationship is expected between Judging and social capital. Because the extent to which people trust others depends on their perceptions of others' self-control [57], traders with Judging personality are more likely to be regarded as trustworthy and reliable by their followers. Besides, research has shown that trustworthy people are more likely to reciprocate a previously received favor [58], strengthening long-term social relationships. Thus, traders with Judging personality have advantages in expanding social network ties and attracting followers. These considerations lead to the following hypothesis:

Hypothesis 2d: While Judging personality is positively associated with traders' social capital, the association is the strongest for structural capital.

Given the above discussion regarding personality types, social capital, and social performance, we draw out the overall conceptual framework, including all the hypotheses and constructs mentioned before, as shown in Figure 1. 


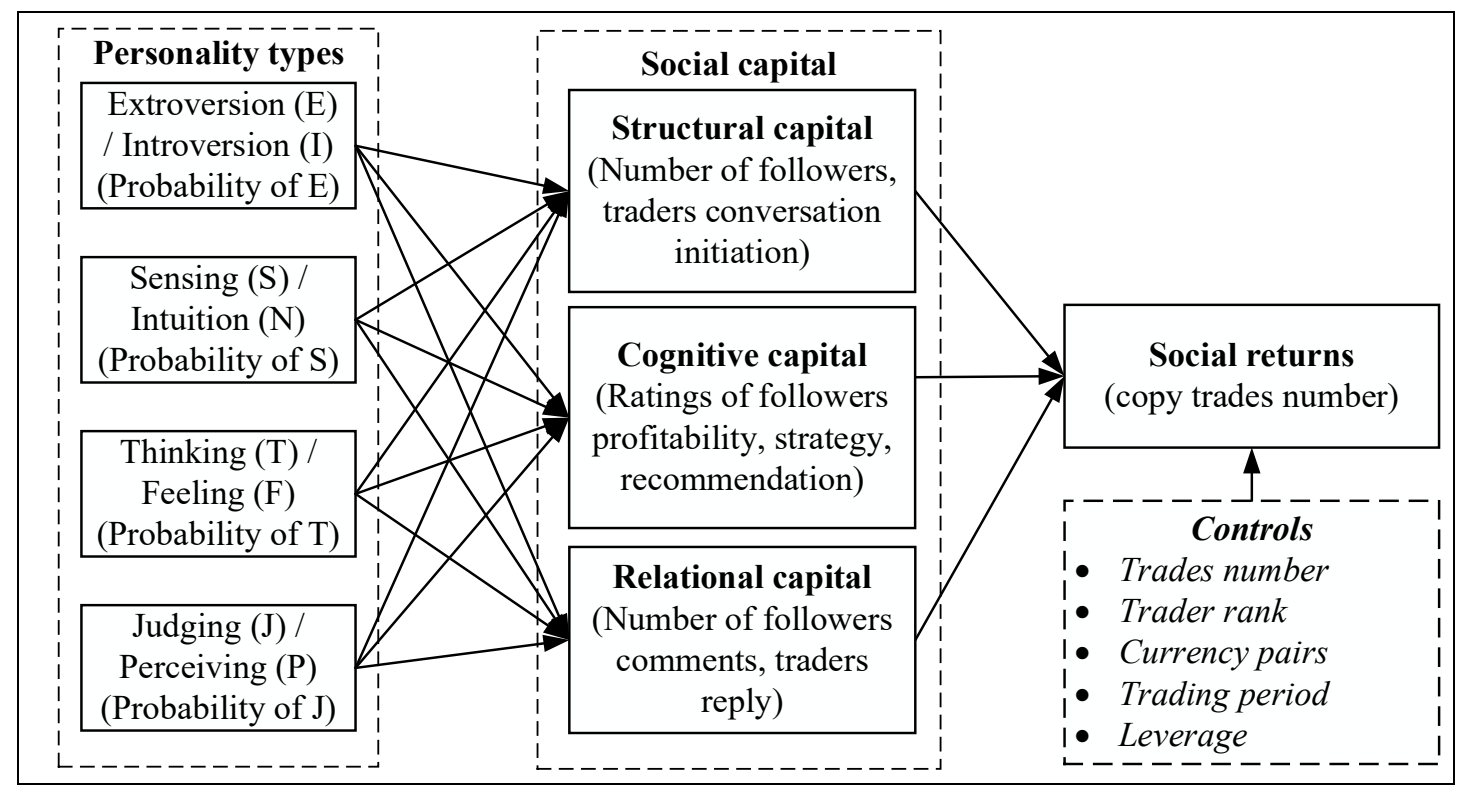

Figure 1. Research Model

\section{Empirical Analysis}

\subsection{Data Collection and Preprocessing}

To validate our proposed research model, data were collected from a pioneering forex social trading platform. Initially, altogether 586 traders were recognized who at least published a single post. Among all the posts released by each trader, we firstly removed any post containing web links. Then, using Python's NLTK package, selective words in the "stop words" (such as "the", "a", "an", "in") list were also taken out to only leave those meaningful content words. Finally, the Python package pattern was applied to lemmatize each word so that inflected forms of the same root word could be transformed into their base form in a dictionary (e.g., "walked", "walks", "walking" all converted into their base form "walk"), which made inflected forms of the base word share one same meaning.

All the text posts of a trader were then integrated and tokenized into just one whole piece of text lemmatized word by word. We then screened out those traders with less than 20 words in all of his or her preprocessed text posts or less than two transactional records in the trader's trading history. In the end, 439 of 586 traders remained to constitute our final dataset.

The ultimate dataset contains 436 traders' basic profile information such as a trader's rank on the platform and the total number of followers. These social text posts were broken down into lemmatized word by word and trading history data with 1,070,821 trading records from November 2008 to August 2020.

\subsection{Personality Prediction Algorithm}

We employed the MBTI personality prediction method proposed by Hernandez and Scott [28] and reported in Mehta et al. [25] as the mean best accuracy to build our model to extract traders' personalities. We used the same popular and common training dataset ${ }^{1}$ based on each user's 50 posts on a particular social personality discussion website but developed our own simple neural network to train and evaluate the personality prediction model. Using the utterly identical partition of test set as divided in Hernandez and Scott [28], our model achieved better accurate performance than the baseline model.

Four different binary classifiers were trained to predict each dimension of MBTI personality. We used the same partition of test set as in Hernandez and Scott [28] by dividing positive and negative samples in the train set. This division was based on the minimum number of positive or negative samples after removing the samples in the test set to guarantee an equal number of samples in both directions in case of overfitting. 10fold cross validation showed that our model achieved an average accuracy of $71.1 \%$, better than $67.8 \%$ obtained by Hernandez and Scott [28].

\footnotetext{
${ }^{1}$ https://www.kaggle.com/datasnaek/mbti-type
} 


\subsection{Variable Operationalization}

Measurement was developed based on indicators commonly used in social trading. Firstly, traders' MBTI personality in each dimension was measured by the predicted class probability calculated from our welltrained personality prediction model. The probability signifies to what extent an individual's personality belongs to that dimension. A higher probability closer to 1 in Extroversion, Sensing, Thinking, Judging indicates a smaller possibility in Introversion, iNtuition, Feeling, Perceiving, respectively. In addition, control variables were directly obtained from traders' basic profile data. Because certain variables in the original dataset exhibited high skewness and kurtosis, exceeding the range of $[-3,3]$ and $[-7,7]$, respectively $[59,60]$, we logarithmically transformed those variables to ensure a normal distribution. Operationalization of each focal construct together with its descriptive statistics are displayed in Table 1 below.

Table 1. Operationalization of Focal Variables and Descriptive Statistics

\begin{tabular}{|c|l|c|c|c|c|}
\hline Variable & \multicolumn{1}{|c|}{ Operationalization } & Mean & Minimum & Maximum & Std Dev \\
\hline E/I & Probability of E & 0.58 & 0.03 & 1.00 & 0.19 \\
\hline S/N & Probability of S & 0.69 & 0.02 & 0.96 & 0.16 \\
\hline $\mathrm{T} / \mathrm{F}$ & Probability of T & 0.58 & 0.00 & 1.00 & 0.21 \\
\hline $\mathrm{J} / \mathrm{P}$ & Probability of J & 0.67 & 0.34 & 1.00 & 0.19 \\
\hline \multirow{2}{*}{$\begin{array}{c}\text { Structural } \\
\text { Capital }\end{array}$} & Number of followers (logarithmic transformation) & 2.31 & 0 & 7.48 & 1.87 \\
\cline { 2 - 5 } & $\begin{array}{l}\text { Number of traders' conversation initiation (logarithmic } \\
\text { transformation) }\end{array}$ & 2.04 & 0 & 6.32 & 1.30 \\
\hline \multirow{2}{*}{$\begin{array}{c}\text { Cognitive } \\
\text { Capital }\end{array}$} & Followers' profitability ratings & 1.85 & 0 & 5 & 1.84 \\
\cline { 2 - 5 } & Followers' strategy ratings & 1.87 & 0 & 5 & 1.85 \\
\cline { 2 - 6 } $\begin{array}{c}\text { Relational } \\
\text { Capital }\end{array}$ & $\begin{array}{l}\text { Numbers of followers' comments (logarithmic } \\
\text { transformation) }\end{array}$ & 1.85 & 0 & 5 & 1.85 \\
\cline { 2 - 6 } & Number of traders' reply (logarithmic transformation) & 0.99 & 0 & 6.36 & 1.43 \\
\hline $\begin{array}{c}\text { Social } \\
\text { Performance }\end{array}$ & Number of copy trades (logarithmic transformation) & 3.16 & 0 & 11.54 & 3.39 \\
\hline
\end{tabular}

\subsection{Measurement Model}

We examined hypotheses using the technique of partial least square with SmartPLS v.3.3.2. The formative measurement model is used to reflect each of the social capital constructs [61]. Discriminant validity was evaluated by contrasting the ratio of the betweentrait correlations to the within-trait correlations using the Heterotrait-Monotrait Ratio (HTMT) of correlations [62]. After the discriminant validity assessment, HTMT values of all variables used in our model were lower than the recommended threshold of 0.85 [62]. It indicated that latent variables could be clearly distinguished, suggesting a good discriminant validity.

\subsection{Hypotheses Testing}

The path coefficients and hypotheses test results of our proposed research model are shown in Table 2 . Analytical results are displayed as follows.

(1) It is found that among three dimensions of social capital, structural capital $\left(\beta_{1}=0.295, \mathrm{P}=0.000\right)$ and cognitive capital $\left(\beta_{2}=0.162, \mathrm{P}=0.002\right)$ was positively correlated with traders' social performance. However, relational capital did not show significance. This might be caused by the shrinking influence generated by quality of social relationships in well-established communities [35]. As leader traders normally own communities with close bonds among members, the role of relational capital in improving social performance is not salient. Therefore, hypothesis H1 was partially supported.

(2) For E/I dimension, it was only found to be significantly positively related to structural capital $\left(\beta_{4}=\right.$ $0.102, \mathrm{P}=0.019)$ and relational capital $\left(\beta_{6}=0.101, \mathrm{P}=\right.$ 0.036 ), but not significantly correlated with cognitive capital, lending partial support to H2a. A possible explanation is that although Extroverts might be good at developing and maintaining a long-term relationship, their innate optimistic characteristics make them hardly influence others' evaluation which is reflected by cognitive capital.

(3) For $\mathrm{S} / \mathrm{N}$ dimension, although it could be found that the negative correlation with structural capital in marginal significance $\left(\beta_{7}=-0.078, \mathrm{P}=0.074\right)$. However, to our disappointment, there was no acceptable significant correlation with any dimension of social capital. This could be interpreted by the less sociable characteristics of Sensing dimension, which take less consideration of socializing with others, 
thereby leading to little development in social capital. Therefore, $\mathrm{H} 2 \mathrm{~b}$ is rejected.

(4) For $T / F$ dimension, it showed negative relationship with structural capital $\left(\beta_{10}=-0.088, \mathrm{P}=\right.$ $0.026)$ and strong negative relationship with cognitive capital $\left(\beta_{11}=-0.155, \mathrm{P}=0.001\right)$ and relational capital $\left(\beta_{12}=-0.184, \mathrm{P}=0.000\right)$, respectively, which fully supported $\mathrm{H} 2 \mathrm{c}$.

Table 2. Results from Hypotheses Testing

\begin{tabular}{|c|c|c|c|c|}
\hline Hypothesis & Construct Relationship & $\beta$ Coefficients & $p$-values & Empirical Support? \\
\hline \multirow{3}{*}{ H1 } & Structural Capital $\rightarrow$ Social Performance & $0.295\left(\beta_{1}\right)$ & $0.000 * * *$ & \multirow{3}{*}{ Partially supported } \\
\hline & Cognitive Capital $\rightarrow$ Social Performance & $0.162\left(\beta_{2}\right)$ & $0.002 * *$ & \\
\hline & Relational Capital $\rightarrow$ Social Performance & $0.044\left(\beta_{3}\right)$ & 0.603 & \\
\hline \multirow{3}{*}{ H2a } & E/I $\rightarrow$ structural capital & $0.102\left(\beta_{4}\right)$ & 0.019* & \multirow{3}{*}{ Partially supported } \\
\hline & E/I $\rightarrow$ cognitive capital & $-0.023\left(\beta_{5}\right)$ & 0.519 & \\
\hline & $\mathrm{E} / \mathrm{I} \rightarrow$ relational capital & $0.101\left(\beta_{6}\right)$ & $0.036 *$ & \\
\hline \multirow{3}{*}{ H2b } & $\mathrm{S} / \mathrm{N} \rightarrow$ structural capital & $-0.078\left(\beta_{7}\right)$ & 0.074 & \multirow{3}{*}{ Not supported } \\
\hline & $\mathrm{S} / \mathrm{N} \rightarrow$ cognitive capital & $-0.032\left(\beta_{8}\right)$ & 0.492 & \\
\hline & $\mathrm{S} / \mathrm{N} \rightarrow$ relational capital & $-0.044\left(\beta_{9}\right)$ & 0.387 & \\
\hline \multirow{3}{*}{$\mathrm{H} 2 \mathrm{c}$} & $\mathrm{T} / \mathrm{F} \rightarrow$ structural capital & $-0.088\left(\beta_{10}\right)$ & $0.026 *$ & \multirow{3}{*}{ Supported } \\
\hline & $\mathrm{T} / \mathrm{F} \rightarrow$ cognitive capital & $-0.155\left(\beta_{11}\right)$ & $0.001 * *$ & \\
\hline & $\mathrm{T} / \mathrm{F} \rightarrow$ relational capital & $-0.184\left(\beta_{12}\right)$ & $0.000 * * *$ & \\
\hline \multirow{3}{*}{ H2d } & $\mathrm{J} / \mathrm{P} \rightarrow$ structural capital & $0.641\left(\beta_{13}\right)$ & $0.000 * * *$ & \multirow{3}{*}{ Supported } \\
\hline & $\mathrm{J} / \mathrm{P} \rightarrow$ cognitive capital & $0.293\left(\beta_{14}\right)$ & $0.000 * * *$ & \\
\hline & $\mathrm{J} / \mathrm{P} \rightarrow$ relational capital & $0.493\left(\beta_{15}\right)$ & $0.000 * * *$ & \\
\hline
\end{tabular}

Notes: $* p<0.05,{ }^{* *} p<0.01,{ }^{* * *} p<0.001$

\subsection{Post-Hoc Analysis}

We also conducted post-hoc analysis to examine the mediating effect of different dimensions of social capital on traders' social performance. The specific indirect effects and total effects of our model are shown in Table 3. The results indicated that structural and cognitive played an important role in mediating social performance. $\mathrm{T} / \mathrm{F}$ and $\mathrm{J} / \mathrm{P}$ were two essential personality dimensions in deciding final social performance. There were significantly negative indirect effect between $\mathrm{T} / \mathrm{F}$, cognitive capital and social performance $\left(\beta_{23}=-0.025\right.$,
(5) For J/P dimension, it was significantly related with all of three dimensions of social capital, with strong positive correlation to structural capital $\left(\beta_{13}=0.641\right.$, $\mathrm{P}$ $=0.000)$, cognitive capital $\left(\beta_{14}=0.293, \mathrm{P}=0.000\right)$ and relational capital $\left(\beta_{15}=0.493, \mathrm{P}=0.000\right)$ respectively. $\mathrm{H} 2 \mathrm{~d}$ was also fully supported.

Table 3. Results from Mediation Analysis

\begin{tabular}{|c|c|c|c|c|}
\hline \multirow{2}{*}{ Relationship } & \multicolumn{2}{|c|}{ Specific Indirect Effects } & \multicolumn{2}{|c|}{ Total Effects } \\
\hline & $\beta$ & $p$-values & $\beta$ & $p$-values \\
\hline $\mathrm{E} / \mathrm{I} \rightarrow$ Structural Capital $\rightarrow$ Social Performance & $0.030\left(\beta_{16}\right)$ & 0.036* & \multirow{3}{*}{$\begin{array}{c}0.031 \\
\left(\beta_{28}\right)\end{array}$} & \multirow{3}{*}{0.108} \\
\hline E/I $\rightarrow$ Cognitive Capital $\rightarrow$ Social Performance & $-0.004\left(\beta_{17}\right)$ & 0.615 & & \\
\hline E/I $\rightarrow$ Relational Capital $\rightarrow$ Social Performance & $0.004\left(\beta_{18}\right)$ & 0.643 & & \\
\hline $\mathrm{S} / \mathrm{N} \rightarrow$ Structural Capital $\rightarrow$ Social Performance & $-0.023\left(\beta_{19}\right)$ & 0.108 & \multirow{3}{*}{$\begin{array}{c}-0.030 \\
\left(\beta_{29}\right)\end{array}$} & \multirow{3}{*}{0.111} \\
\hline $\mathrm{S} / \mathrm{N} \rightarrow$ Cognitive Capital $\rightarrow$ Social Performance & $-0.005\left(\beta_{20}\right)$ & 0.494 & & \\
\hline S/N $\rightarrow$ Relational Capital $\rightarrow$ Social Performance & $-0.002\left(\beta_{21}\right)$ & 0.739 & & \\
\hline $\mathrm{T} / \mathrm{F} \rightarrow$ Structural Capital $\rightarrow$ Social Performance & $-0.026\left(\beta_{22}\right)$ & 0.082 & \multirow{2}{*}{$\begin{array}{c}-\mathbf{- 0 . 0 5 9} \\
\left(\beta_{30}\right)\end{array}$} & \multirow{2}{*}{$0.002 * *$} \\
\hline $\mathrm{T} / \mathrm{F} \rightarrow$ Cognitive Capital $\rightarrow$ Social Performance & $-0.025\left(\beta_{23}\right)$ & 0.018* & & \\
\hline
\end{tabular}




\begin{tabular}{|c|c|c|c|c|}
\hline $\mathrm{T} / \mathrm{F} \rightarrow$ Relational Capital $\rightarrow$ Social Performance & $-0.008\left(\beta_{24}\right)$ & 0.613 & & \\
\hline $\mathrm{J} / \mathrm{P} \rightarrow$ Structural Capital $\rightarrow$ Social Performance & $0.189\left(\beta_{25}\right)$ & $0.000 * * *$ & \multirow{3}{*}{$\begin{array}{c}\mathbf{0 . 2 5 8} \\
\left(\beta_{31}\right)\end{array}$} & \multirow{3}{*}{$0.000 * * *$} \\
\hline $\mathrm{J} / \mathrm{P} \rightarrow$ Cognitive Capital $\rightarrow$ Social Performance & $0.047\left(\beta_{26}\right)$ & $0.008 * *$ & & \\
\hline $\mathrm{J} / \mathrm{P} \rightarrow$ Relational Capital $\rightarrow$ Social Performance & $0.022\left(\beta_{27}\right)$ & 0.602 & & \\
\hline
\end{tabular}

Notes: $* p<0.05, * * p<0.01,{ }^{* * *} p<0.001$

\section{Discussion and Future Plans}

The uprising of social trading has aroused an increasing number of research interests on the scrutiny of traders' trading profitability on such platforms. However, social performance profited from their followers is still underexplored. Social trading platforms enable a unique source of profit for leader traders by providing copy trading function to monetize their social performance. Therefore, traders' social performance is an important indicator to evaluate their potential in such platforms. In addition, traders' innate personality traits influence both the quantity and quality of their social relationships, leading to social performance. Drawing on social capital theory, this study disentangles the complicated influencing mechanism of traders' personalities on their social performance. We argue that personality shapes traders' ability to accumulate social capital embedded within the online social trading community, affecting their social performance. Empirical results show that structural and cognitive capital positively impact traders' social performance, while relational capital does not significantly influence it. The personality dimensions of $\mathrm{T} / \mathrm{F}$ and $\mathrm{J} / \mathrm{P}$ exert negative and positive impacts on all social capital dimensions. Although there is a significantly positive relationship between $\mathrm{E} / \mathrm{I}$ and structural and relational capital, $\mathrm{S} / \mathrm{N}$ does not exhibit a significantly negative relationship with any dimension of social capital. Post-hoc analysis displays that $\mathrm{T} / \mathrm{F}$, and $\mathrm{J} / \mathrm{P}$ are predominant personality dimensions in determining traders' social performance.

Our study aims to contribute to the extant literature in two folds. Firstly, this study addresses the role of traders' personalities in influencing their social performance, enriching the relative dearth of literature on traders' social interaction [13]. Our study provides empirical support to the positive role of $\mathrm{E} / \mathrm{I}$ and $\mathrm{J} / \mathrm{P}$ personality in improving social performance of traders. Secondly, we recognize social capital embedded in trading communities as the key mediating mechanism through which traders' personality impacts their social performance. Our results show that $\mathrm{E} / \mathrm{I}$ and $\mathrm{J} / \mathrm{P}$ personality give rise to a favorable atmosphere in trading communities delineated by structural, cognitive, and relational capital, enhancing traders' social performance. Social capital theory is thus extended to understand how to reap social benefits from online trading communities.

Findings in this study also generate practical implications. By examining the relationship between personality, social capital, and social performance, this study attests to the critical role of traders' personalities in cultivating a favorable online community atmosphere to maintain active social interactions and attract new followers. Social trading platforms are suggested to develop their communities by filtering traders with prosocial personalities to bring about more prosperous social capital [3]. Besides, the textbased personality mining approach developed in this research can also be used by platforms to develop an automatic extraction technique that could identify traders' personality types based on their historical interaction data, which is more precise than subjective measures. As for existing traders on these social trading platforms, the platforms could leverage findings of this study to develop customized treatment for traders with different personalities to facilitate them achieving a high level of social performance. For example, traders with more prosocial personalities could be given priority in recommendation algorithms to increase their exposure to followers.

As for the next steps of this research, we will firstly utilize different frameworks (e.g., Big-Five model) to identify more personality dimensions, potentially generating more insights on this topic. Secondly, it is notable that our initial results only provide partial support to hypotheses. Therefore, we will further investigate the mechanism underlying each unsupported relationship to understand underlying reasons. Thirdly, alternative indicators measuring social capital will be incorporated, serving as robustness checks to our findings.

\section{Acknowledgement}

This work was supported by the program of China Scholarship Council (CSC NO. 202006230299 and 201906340142), the National Natural Science Foundation of China (NSFC: 71801204), the Zhejiang Soft Science Programme (2021C35017), and the Ningbo Commonweal Science and Technology Fund (202002N3138). 


\section{References}

[1] Glaser, F. and M. Risius, "Effects of Transparency: Analyzing Social Biases on Trader Performance in Social Trading", Journal of Information Technology, 2018. 33(1): pp. 19-30.

[2] Roder, F. and A. Walter, "What Drives Investment Flows into Social Trading Portfolios?", Journal of Financial Research, 2019. 42(2): pp. 383-411.

[3] Doering, P., S. Neumann, and S. Paul. "A Primer on Social Trading Networks-Institutional Aspects and Empirical Evidence", in EFMA Annual Meetings. 2015.

[4] Liu, L.L. and R. Du. "Roles of Community Commitment and Community Atmosphere: An Empirical Study of Online Community Success", in Twelfth Wuhan International Conference on E-Business. 2013.

[5] Andrews, D.C., "Audience-Specific Online Community Design", Communications of the ACM, 2002. 45(4): pp. 64-68.

[6] Hew, K.F., "Determinants of Success for Online Communities: An Analysis of Three Communities in Terms of Members' Perceived Professional Development", Behaviour \& Information Technology, 2009. 28(5): pp. 433-445.

[7] Mund, M., B.F. Jeronimus, and F.J. Neyer, "Personality and Social Relationships: As Thick as Thieves", in Personality and Disease. 2018, Academic Press: San Diego. pp. 153-183.

[8] Back, M.D., A. Baumert, J.J.A. Denissen, F.M. Hartung, L. Penke, S.C. Schmukle, F.D. Schonbrodt, M. Schroder-Abe, M. Vollmann, J. Wagner, and C. Wrzus, "PERSOC: A Unified Framework for Understanding the Dynamic Interplay of Personality and Social Relationships", European Journal of Personality, 2011. 25(2): pp. 90-107.

[9] Asendorpf, J.B. and S. Wilpers, "Personality Effects on Social Relationships", Journal of Personality and Social Psychology, 1998. 74(6): pp. 1531-1544.

[10] Adali, S. and J. Golbeck. "Predicting Personality with Social Behavior", in 2012 IEEE/ACM International Conference on Advances in Social Networks Analysis and Mining. 2012.

[11] Burt, R.S., "Structural holes". 1992, Cambridge, MA: Harvard University Press.

[12] Pan, W., Y. Altshuler, and A. Pentland, "Decoding Social Influence and the Wisdom of the Crowd in Financial Trading Network", 2012 International Conference on Privacy, Security, Risk and Trust and 2012 International Confernece on Social Computing, 2012: pp. 203-209.

[13] Jin, X.J., Y. Zhu, and Y.S. Huang, "Losing by Learning? A Study of Social Trading Platform", Finance Research Letters, 2019. 28: pp. 171-179.

[14] Nahapiet, J. and S. Ghoshal, "Social Capital, Intellectual Capital, and the Organizational Advantage", Academy of Management Review, 1998. 23(2): pp. 242-266.

[15] Oehler, A., M. Horn, and S. Wendt, "Benefits from Social Trading? Empirical Evidence for Certificates on
Wikifolios", International Review of Financial Analysis, 2016. 46: pp. 202-210.

[16] Heimer, R.Z., "Peer Pressure: Social Interaction and the Disposition Effect", Review of Financial Studies, 2016. 29(11): pp. 3177-3209.

[17] Wohlgemuth, V., E.S.C. Berger, and M. Wenzel, "More Than Just Financial Performance: Trusting Investors in Social Trading”, Journal of Business Research, 2016. 69(11): pp. 4970-4974.

[18] De Bortoli, D., N. da Costa, M. Goulart, and J. Campara, "Personality Traits and Investor Profile Analysis: A Behavioral Finance Study", Plos One, 2019. 14(3): pp. e0214062.

[19] Tauni, M.Z., S. Yousaf, and T. Ahsan, "InvestorAdvisor Big Five Personality Similarity and Stock Trading Performance", Journal of Business Research, 2020. 120: pp. 49-63.

[20] Vora, H., M. Bhamare, and D.K.A. Kumar, "Personality Prediction from Social Media Text: An Overview", International Journal of Engineering Research \& Technology, 2020. 9(05): pp. 352-357.

[21] Roberts, B.W. and D. Mroczek, "Personality Trait Change in Adulthood", Current Directions in Psychological Science, 2008. 17(1): pp. 31-35.

[22] Matthews, G., I.J. Deary, and M.C. Whiteman, "Personality Traits". 2009, England: Cambridge University Press.

[23] Costa, P.T. and R.R. McCrae, "Revised NEO Personality Inventory (NEO-PI-R) and Neo FiveFactor Inventory (NEO-FFI)”. 1992: Psychological Assessment Resources.

[24] Myers, I.B., M.H. McCaulley, and R. Most, "Manual, A Guide to the Development and Use of the MyersBriggs Type Indicator". 1985: Consulting Psychologists Press.

[25] Mehta, Y., N. Majumder, A. Gelbukh, and E. Cambria, "Recent Trends in Deep Learning Based Personality Detection", Artificial Intelligence Review, 2020. 53(4): pp. 2313-2339.

[26] Celli, F. and B. Lepri. "Is Big Five Better than MBTI? A Personality Computing Challenge Using Twitter Data", in CLiC-it. 2018.

[27] Furnham, A., J. Moutafi, and J. Crump, "The Relationship Between the Revised NEO-Personality Inventory and the Myers-Briggs Type Indicator", Social Behavior and Personality, 2003. 31(6): pp. 577584.

[28] Hernandez, R. and I. Scott. "Predicting Myers-Briggs Type Indicator with Text", in 31st Conference on Neural Information Processing Systems (NIPS 2017). 2017.

[29] Coleman, J.S., "Social Capital in the Creation of Human-Capital", American Journal of Sociology, 1988. 94: pp. S95-S120.

[30] Lin, N., "Building a Network Theory of Social Capital", CONNECTIONS. 22(1): pp. 28-51.

[31] Wellman, B. and S. Wortley, "Different Strokes from Different Folks - Community Ties and Social Support", American Journal of Sociology, 1990. 96(3): pp. 558588 . 
[32] Uphoff, N. and C.M. Wijayaratna, "Demonstrated Benefits from Social Capital: The Productivity of Farmer Organizations in Gal Oya, Sri Lanka", World Development, 2000. 28(11): pp. 1875-1890.

[33] Huang, K.-Y., I. Chengalur-Smith, and A. Pinsonneault, "Sharing Is Caring: Social Support Provision and Companionship Activities in Healthcare Virtual Support Communities", MIS Quarterly, 2019. 43(2): pp. 395-424.

[34] Granovetter, M., "Economic-Action and SocialStructure - the Problem of Embeddedness", American Journal of Sociology, 1985. 91(3): pp. 481-510.

[35] Bolino, M.C., W.H. Turnley, and J.M. Bloodgood, "Citizenship Behavior and the Creation of Social Capital in Organizations", Academy of Management Review, 2002. 27(4): pp. 505-522.

[36] Inkpen, A.C. and E.W.K. Tsang, "Social Capital, Networks, and Knowledge Transfer", Academy of Management Review, 2005. 30(1): pp. 146-165.

[37] Tsai, W.P. and S. Ghoshal, "Social Capital and Value Creation: The Role of Intrafirm Networks", Academy of Management Journal, 1998. 41(4): pp. 464-476.

[38] Annen, K., "Social Capital, Inclusive Networks, and Economic Eerformance", Journal of Economic Behavior \& Organization, 2003. 50(4): pp. 449-463.

[39] Fafchamps, M. and B. Minten, "Returns to Social Network Capital among Traders", Oxford Economic Papers-New Series, 2002. 54(2): pp. 173-206.

[40] Shive, S., "An Epidemic Model of Investor Behavior", Journal of Financial and Quantitative Analysis, 2010. 45(1): pp. 169-198.

[41] Han, B., D. Hirshleifer, and J. Walden, "Social Transmission Bias and Investor Behavior". 2018, National Bureau of Economic Research.

[42] Tulin, M., B. Lancee, and B. Volker, "Personality and Social Capital", Social Psychology Quarterly, 2018. 81(4): pp. 295-318.

[43] Scheufele, D.A. and D.V. Shah, "Personality Strength and Social Capital - The Role of Dispositional and Informational Variables in the Production of Civic Participation", Communication Research, 2000. 27(2): pp. 107-131.

[44] Weiqin, E.L., M. Campbell, M. Kimpton, K. Wozencroft, and A. Orel, "Social Capital on Facebook: The Impact of Personality and Online Communication Behaviors", Journal of Educational Computing Research, 2016. 54(6): pp. 747-768.

[45] James, W., "The Principles of Psychology", in The Principles of Psychology. 1905. pp. 689-689.

[46] Burt, R.S., J.E. Jannotta, and J.T. Mahoney, "Personality Correlates of Structural Holes", Social Networks, 1998. 20(1): pp. 63-87.

[47] Fang, R.L., B. Landis, Z. Zhang, M.H. Anderson, J.D. Shaw, and M. Kilduff, "Integrating Personality and Social Networks: A Meta-Analysis of Personality, Network Position, and Work Outcomes in Organizations", Organization Science, 2015. 26(4): pp. 1243-1260.

[48] Dunbar, R.I.M., "The social brain hypothesis", Evolutionary Anthropology, 1998. 6(5): pp. 178-190.
[49] Goby, V.P., "Personality and Online/Offline Choices: MBTI Profiles and Favored Communication Modes in A Singapore Study", Cyberpsychology \& Behavior, 2006. 9(1): pp. 5-13.

[50] Cho, H.C., G. Gay, B. Davidson, and A. Ingraffea, "Social Networks, Communication Styles, and Learning Performance in A CSCL Community", Computers \& Education, 2007. 49(2): pp. 309-329.

[51] Woolcock, M., "The Place of Social Capital in Understanding Social and Economic Outcomes", Canadian Journal of Policy Research, 2001. 2(1): pp. 11-17.

[52] Bayne, R. and P. Corr., "The Myers-Briggs Type Indicator: A Critical Review and Practical Guide", Personality and Individual Differences, 1996. 20(6): pp. 809-809.

[53] Selden, M. and A.S. Goodie, "Review of the Effects of Five Factor Model Personality Traits on Network Structures and Perceptions of Structure", Social Networks, 2018. 52: pp. 81-99.

[54] Ashton, M.C., K. Lee, and S.V. Paunonen, "What Is the Central Feature of Extraversion? Social Attention versus Reward Sensitivity", Journal of Personality and Social Psychology, 2002. 83(1): pp. 245-252.

[55] Klein, K.J., B.C. Lim, J.L. Saltz, and D.M. Mayer, "How Do They Get There? An Examination of the Antecedents of Centrality in Team Networks", Academy of Management Journal, 2004. 47(6): pp. 952-963.

[56] Mayfield, C.O., G. Perdue, and K.C. Wooten, "Investment Management and Personality Type", Financial Services Review, 2008. 17: pp. 219.

[57] Righetti, F. and C. Finkenauer, "If You Are Able to Control Yourself, I Will Trust You: The Role of Perceived Self-Control in Interpersonal Trust", Journal of Personality and Social Psychology, 2011. 100(5): pp. 874-886.

[58] Dohmen, T., A. Falk, D. Huffman, and U. Sunde, "Representative Trust and Reciprocity: Prevalence and Determinants", Economic Inquiry, 2008. 46(1): pp. 8490.

[59] Hair, J., R. Anderson, B. Babin, and W. Black, "Multivariate Data Analysis: A Global Perspective". 2010: Pearson Upper Saddle River, New Jersey.

[60] Byrne, B.M., "Structural Equation Modeling with AMOS: Basic Concepts, Applications, and Programming, 2nd Edition". 2010: New York: Roudledge Taylor \& Francis Group.

[61] Diamantopoulos, A., "Incorporating Formative Measures into Covariance-Based Structural Equation Models", Mis Quarterly, 2011. 35(2): pp. 335-358.

[62] Henseler, J., C.M. Ringle, and M. Sarstedt, "A New Criterion for Assessing Discriminant Validity in Variance-Based Structural Equation Modeling", Journal of the Academy of Marketing Science, 2015. 43(1): pp. 115-135. 